\title{
The anticancer effects of MPTOG211, a novel HDAC6 inhibitor, combined with chemotherapeutic agents in human acute leukemia cells
}

\author{
Huang-Ju Tu', Yi-Jyun Lin', Min-Wu Chao ${ }^{2}$, Ting-Yi Sung ${ }^{3}$, Yi-Wen Wu' ${ }^{4}$ Yi-Ying Chen², Mei-Hsiang Lin ${ }^{5}$,
} Jing-Ping Liou ${ }^{5}$, Shiow-Lin Pan ${ }^{2,6}$ and Chia-Ron Yang ${ }^{1 *}$ (i)

\begin{abstract}
Background: There are some limitations of standard chemotherapy for acute leukemia. Vincristine and doxorubicin are commonly used for acute leukemia, but they may induce serious side effects such as cardiomyopathy and neurotoxicity. Furthermore, chemotherapy resistance occurs more and more frequently. Therefore, effective treatment strategies are needed. Histone deacetylase 6 inhibition is considered as a potential therapeutic strategy for acute leukemia, since it is observed that HDAC6 is overexpressed in acute leukemia and regulates tumor survival. Combination therapy for cancer is used to minimize adverse drug effects, reduce drug dosage, enhance efficacy, and prevent drug resistance. In order to improve efficacy of chemotherapy agents of acute leukemia, this study will investigate the effects of combination MPTOG211, a novel histone deacetylase 6 inhibitor, with doxorubicin or vincristine on human acute leukemia cells.

Results: MPTOG211 combined with doxorubicin induces DNA damage response on human acute myeloid leukemia cells. MPTOG211 can additionally increase Ku70 acetylation and release BAX to mitochondria. Ectopic expression of HDAC6 successively reversed the apoptosis triggered by the combined treatment. Moreover, co-treatment of MPTOG211 and vincristine may alter microtubule dynamics, triggering acute lymphoblastic leukemia cells arrest in mitotic phase followed by induction of the apoptotic pathway. Finally, MPTOG211 plus doxorubicin or vincristine can significantly improve the tumor growth delay in a tumor xenograft model.
\end{abstract}

Conclusions: Collectively, our data highlighted that MPTOG211 in combination with chemotherapy drugs has significant anticancer activity, suggesting a novel strategy for the treatment of acute leukemia.

Keywords: Histone deacetylase 6, Acute leukemia, Combination therapy, Ku70, Microtubule dynamics

\section{Background}

Leukemia is a hematologic malignancy caused by the rapid proliferation of abnormal blood cells. This disease may be acute or chronic. In the former type, most cancer cells remain in a more immature and frequently dividing "blast" form, which leads to a range of complications and is fatal without proper treatment [1].

\footnotetext{
* Correspondence: cryang@ntu.edu.tw

'School of Pharmacy, College of Medicine, National Taiwan University, No.33, Linsen S. Road, Taipei 10050, Taiwan

Full list of author information is available at the end of the article
}

Acute leukemia can be further divided in two subtypes by lineage. Of these, acute lymphocytic leukemia (ALL), which is characterized by the abnormal proliferation of lymphocytes (e.g., B cells and T cells), is the most common type of pediatric cancer. Acute myeloid leukemia (AML) involves the abnormal proliferation of immature myeloid progenitors (e.g., granulocytes, monocytes, red blood cells, and platelets). Both subtypes can progress quickly but differ considerably in terms of survival (5 year survival: $67.5 \%$ and $25.9 \%$ for ALL and AML, respectively) [2].

(c) The Author(s). 2018 Open Access This article is distributed under the terms of the Creative Commons Attribution 4.0 International License (http://creativecommons.org/licenses/by/4.0/), which permits unrestricted use, distribution, and 
Currently, the chemotherapeutic agents vincristine (VCR) and doxorubicin (DOXO) are often used to treat acute leukemia. However, the clinical use of these drugs is often limited by the risk of side effects such as cardiomyopathy [3] and neurotoxicity [4]. Accordingly, safer, effective treatment strategies for acute leukemia are needed.

Histone deacetylases (HDACs) enzymatically regulate DNA expression by removing acetyl groups from histones. As a result, DNA can more tightly wind around histones, thereby decreasing gene expression [5]. Mammals harbor four classes of HDACs, which can be distinguished by structure, enzymatic function, subcellular localization, and expression pattern [6]. Notably, HDAC overexpression has been identified in many types of cancer, indicating that HDACs' activity may be a promising therapeutic target for cancer management [7]. To date, the US Food and Drug Administration has approved four pan-HDAC inhibitors for the treatment of various cancers, especially hematological malignancies such as cutaneous $\mathrm{T}$ cell lymphoma [8], peripheral $\mathrm{T}$ cell lymphoma [9], and multiple myeloma [10]. Although pan-HDAC inhibitors differ in terms of chemical structure, they are similarly cardiotoxic, and therefore, their clinical utility is limited [11]. Emerging evidence shows a potential association of pan-HDAC inhibitor-induced cardiotoxicity with specific HDAC isoforms, leading to an interest in isoform selectivity in the field of drug development [12].

The HDAC family member HDAC6 resides mainly in the cytoplasm, where it plays a unique role in regulating non-histone proteins without affecting gene expression [13]. Many types of cancers express high levels of HDAC6 [14-16], and this overexpression can be exploited for treatment purposes. For example, the synergistic effects of HDAC6 inhibition and bortezomib induced apoptotic cell death in ovarian cancer cells [17], whereas HDAC6 knockdown markedly reduced the migration and invasion activity of hepatocellular carcinoma cells [18]. Another recent study identified HDAC6 as an important regulator of the cytoskeleton, which is a required component for invasive activity in breast cancer cells [19].

In the present study, we evaluated the effects of a novel, selective HDAC6 inhibitor, MPT0G211, in acute leukemia cells when administered alone or in combination with chemotherapy drugs. We found that in AML cells, MPT0G211 potentiated the cytotoxic effects of DOXO by impairing DNA repair machinery and activating Bcl-2-associated $\mathrm{X}$ protein (BCL-XL)-dependent cell apoptosis. Additionally, when combined with VCR, MPT0G211 disrupted microtubule dynamics to induce mitotic arrest in ALL cells. These data suggest that HDAC6 inhibition represents a novel opportunity in the treatment of acute leukemia.

\section{Materials and methods}

\section{Cell lines}

The human acute myeloid leukemia cell line, HL-60, human acute lymphoblastic leukemia cell line, MOLT-4, and human umbilical vein endothelial cells (HUVEC) were obtained from Bioresource Collection and Research Center (Taiwan). Cells were maintained in RPMI-1640 medium supplemented with $10 \%(v / v)$ fetal bovine serum (Gibco, Carlsbad, CA, USA) and $1 \%$ of a mixture of penicillin-streptomycin-amphotericin B (Kibbutz Beit Haemek, Israel). For HDAC6 overexpressed cells, HL-60 cells were transfected with HDAC6-FLAG (Plasmid \#13823, Addgene Inc., Cambridge, MA, USA) by using Turbofect (Thermo Fisher Scientific, Rockford, IL, USA). All cells were cultured at $37^{\circ} \mathrm{C}$ in a humidified atmosphere with $5 \% \mathrm{CO} 2$.

\section{Chemicals and antibodies}

MPT0G211, tubastatin A (TBA), and SAHA were synthesized by Dr. Jing-Ping Liou's Lab. (School of Pharmacy, College of Pharmacy, Taipei Medical University, Taiwan), and the purity are more than $98 \%$. Doxorubicin (DOXO), cyclophosphamide (CTX), and vincristine (VCR) was obtained from Cayman Chemical (Ann Arbor, MI, USA). Antibodies against BCL-2, BCL-XL, cleaved caspase 3, caspase 8 , caspase 9 , acetyl- $\alpha$-tubulin, acetyl-histone 3 , histone 3, HDAC6, survivin, p-ATM, p-ATR, p-CHK1, CHK1, cyclin B1, aurora B, p-PLK1, p-H3S10, p-CDC2 (Y15), and p-CDC2 (T161) were purchased from Cell signaling (Danvers, MA, USA). $\alpha$-Tubulin, $\gamma$-H2AX, ATM, ATR, BAX, cytochrome c, and COX IV were from Genetex (Irvine, CA, USA). PARP and CDC2 were from Santa Cruz Biotechnology (Dallas, TX, USA).

\section{Cell viability assay}

Cells were seeded in a 24-well plate at a density of $1 \times 10^{6}$ cells/well and then treated with various concentrations of MPT0G211, TBA, DOXO, VCR or CTX alone or in combination treatment for $48 \mathrm{~h}$. MTT solution (final concentration $0.5 \mathrm{mg} / \mathrm{ml}$ ) was then added to the 24-well plate in the dark, and the plate was incubated at $37^{\circ} \mathrm{C}$ for $2 \mathrm{~h}$. For HL-60 cells, $10 \%$ SDS were added in the wells to dissolved the crystal, and for HUVEC cells, MTT-containing medium were removed and DMSO were added to each well to lyse cells; the absorbance was spectrophotometrically analyzed at $570 \mathrm{~nm}$.

\section{Protein extraction and Western blot}

Cells were treated with indicated condition and then lysed in lysis buffer ( $10 \mathrm{mmol} / \mathrm{L}$ Tris- $\mathrm{HCl}$ (pH 7.4), 150 $\mathrm{mmol} / \mathrm{L} \mathrm{NaCl}, 1 \mathrm{mmol} / \mathrm{L}$ EGTA, $1 \mathrm{mmol} / \mathrm{L}$ PMSF, $10 \mu \mathrm{g} / \mathrm{mL}$ aprotinin, $10 \mu \mathrm{g} / \mathrm{mL}$ leupeptin, $1 \mathrm{mM}$ sodium 
orthovandate, $1 \mathrm{mM} \mathrm{NaF}$, and $1 \%$ Triton X-100) for 30 min and centrifuged at $13,000 \mathrm{rpm}$. The supernatants were quantified by BCA Protein Assay Kit (Thermo Fisher Scientific, Rockford, IL, USA). Equal amounts of protein were separated by SDS-PAGE and then transferred to PVDF membranes. The membranes were blotted with different antibodies overnight at $4{ }^{\circ} \mathrm{C}$ and conjugated with appropriate secondary antibodies.

\section{Immunoprecipitation}

After treated with MPT0G211, TBA, or DOXO, cells were lysed in lysis buffer containing Halt ${ }^{\mathrm{ma}}$ protease and phosphatase inhibitor (Thermo Fisher Scientific, Rockford, IL, USA). Meanwhile, Protein A Magnetic Beads (Bio-Rad, Hercules, CA, USA) were incubated with capture antibodies and rotated $10 \mathrm{~min}$ at room temperature. The mixture was rinsed with PBST three times to remove unbounded antibodies and incubated with cell lysate for 1 h. The complexes captured by magnetic rack were then washed three times using PBST to remove unbound proteins. All immunoprecipitation samples were suspended in Laemmli sample buffer and boiled for $10 \mathrm{~min}$. The complex proteins were then analyzed by Western blotting.

\section{Flow cytometry}

After the treatment of vehicle (0.1\% DMSO), MPT0G211, TBA, or chemotherapy agents for the indicated time courses, the cells were fixed with $75 \%(v / v)$ alcohol at $4{ }^{\circ} \mathrm{C}$ overnight. After centrifugation, cells were incubated in DNA extraction buffer $\left(0.2 \mathrm{M} \mathrm{NaHPO}_{4}-0.1 \mathrm{M}\right.$ citric acid $)$ for $20 \mathrm{~min}$ at room temperature. Then, the cells were centrifuged and resuspended with $0.5 \mathrm{~mL}$ PI solution $(1 \%$ Triton X-100, $100 \mu \mathrm{g} / \mathrm{mL}$ RNAase A and $80 \mu \mathrm{g} / \mathrm{mL}$ propidium iodide). Evolution of the cell cycle histogram was analyzed with the FACScan and CellQuest software (Becton Dickinson).

\section{Cellular dissection method}

Nuclear/Cytosol Fractionation Kit (Biovision, Inc., Milpitas, CA, USA) was used to separate cytosol and nuclear. Briefly, cells were collected and centrifuged at $600 \mathrm{~g}$ for 5 min, supernatants were removed, and lysate were resuspended in Cytosol Extraction Buffer-A, vortex vigorously for $15 \mathrm{~s}$ and placed on ice for $10 \mathrm{~min}$. Cytosol Extraction Buffer-B were then added to the mixture, vortex for $5 \mathrm{~s}$, incubated on ice for $1 \mathrm{~min}$, and centrifuged at 14,500 rpm to acquire cytosolic fraction. The remaining pallets were resuspended in nuclear extraction buffer, vortex the sample for $15 \mathrm{~s}$, and returned the sample to ice for $10 \mathrm{~min}$. After repeated for four times, samples were centrifuged at $14,500 \mathrm{rpm}$ to acquire nuclear extraction.

Cytochrome c Releasing Apoptosis Assay Kit (Biovision, Inc., Milpitas, CA, USA) was used to separate mitochondria and cytosol. Briefly, cells were centrifuged at $600 \mathrm{~g}$ for $5 \mathrm{~min}$, supernatant was removed, and cytosol extraction buffer was added for $10 \mathrm{~min}$. Cells were homogenized in an ice-cold Dounce tissue grinder and transferred homogenate to a new tube. The mixture was centrifuged at $700 \mathrm{~g}$ for $10 \mathrm{~min}$, supernatant was collected into a fresh tube and centrifuged at 10,000 $g$ for 30 min to acquire cytosolic fraction. The pellet was resuspended in mitochondrial extraction buffer and vortex $10 \mathrm{~s}$ to obtain mitochondria fraction.

\section{Immunofluorescence}

To observe microtubule distribution, cells were treated with MPT0G211, TBA alone, or in combination with vincristine for $24 \mathrm{~h}$. The cells were fixed with $4 \%$ paraformaldehyde for $15 \mathrm{~min}$ then permeabilized with $0.1 \%$ Tritin $\mathrm{X}-100$ for $10 \mathrm{~min}$. After washing with PBST for several times, 4\% BSA were used to block non-specific proteins for $1 \mathrm{~h}$ then washed with PBST again and incubated with primary antibody $\alpha$-tubulin for $2 \mathrm{~h}$. FITC-conjugated anti-mouse IgG antibody were then used for another $2 \mathrm{~h}$. Finally, cover slides were recovered to the slides with mounting gel containing DAPI stain. Images were detected and captured with the ZEISS confocal microscope.

\section{Tumor xenograft model}

Seven-week-old male severe combined immunodeficiency mice were fed ad libitum water and Pico-Lab Rodent Diet. All procedures were performed in accordance with the NIH guidelines on laboratory animal welfare approved by the Animal Use and Management Committee of Taipei Medical University (IACUC No. LAC2015-0163). HL-60 or MOLT- 4 cells $\left(1 \times 10^{7}\right.$ cells in 0.2 $\mathrm{ml} \mathrm{PBS}$ ) were subcutaneously injected into the flanks of the mice. When tumor sizes reached $200 \mathrm{~mm}^{3}$, mice were randomized into four groups with an indicated dosage of DOXO, VCR, and MPT0G211 alone or in combination treatment. All mouse tumors were allowed to reach an endpoint volume of $1200 \mathrm{~mm}^{3}$.

\section{Statistical analysis}

All data were expressed as mean values \pm S.E.M. and were done independently three times. The significance of differences between the experimental groups and controls was assessed by Student's $t$ test. $P<0.05$ was considered statistically significant $(" p<0.05 ; * 0<0.01 ; * * * * p$ $<0.001$; compared with the respective control group).

\section{Results}

MPTOG211 induces apoptosis in acute leukemia cells

In our previous study, we showed that MPT0G211 is a selective HDAC6 inhibitor with more potent activity than the currently available HDAC6 inhibitor ACY-1215 [20]. In this study, we examined the inhibitory effects of MPT0G211 on HDAC6 activity in acute leukemia cells. 
As shown in Fig. 1a, MPT0G211 more strongly induced $\alpha$-tubulin acetylation when compared with tubastatin A (TBA) without affecting histone 3 acetylation in both HL-60 human acute myeloid leukemia cells and MOLT-4 human acute lymphoblastic leukemia cells. Furthermore, MPT0G211 inhibited HDAC6 enzyme activity without significantly affecting the HDAC6 protein levels.
We additionally used an MTT assay to evaluate the effects of HDAC6 inhibitors on the viability of acute leukemia cells (Fig. 1b). Notably, MPT0G211 more effectively induced HL-60 and MOLT-4 cell death $\left(\mathrm{IC}_{50}=5.06\right.$ \pm 0.12 and $3.79 \pm 0.36 \mu \mathrm{M}$, respectively), compared with TBA ( $\mathrm{IC}_{50}>10 \mu \mathrm{M}$ for both cell types), but had no cytotoxic effect on normal human umbilical vein endothelial

A
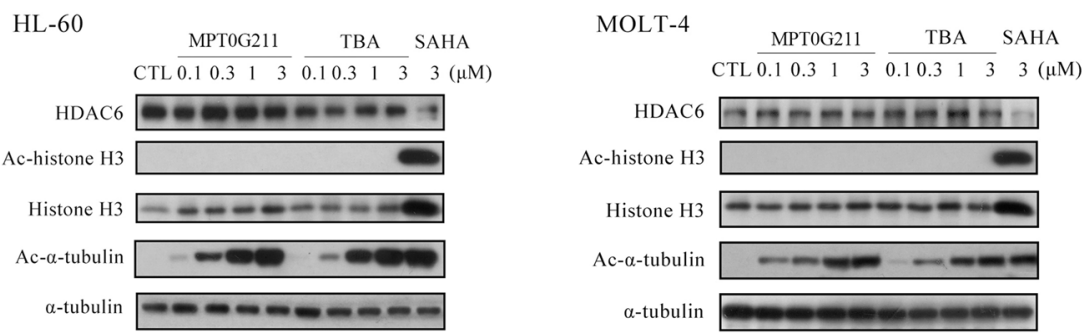

B
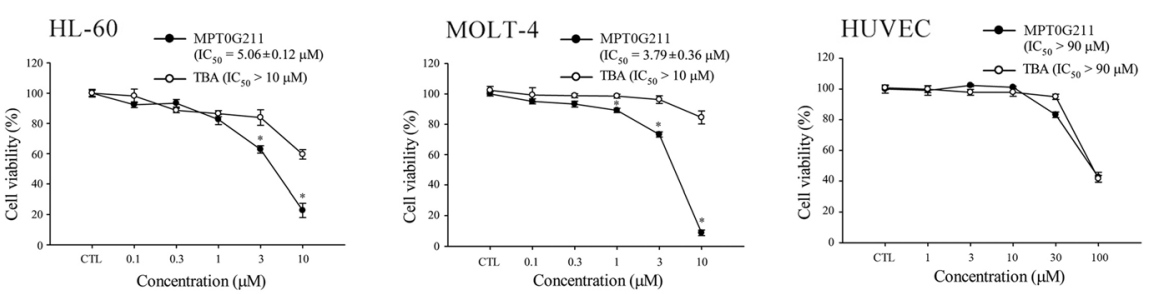

C HL-60

MPT0G211 ( $\mu \mathrm{M})$
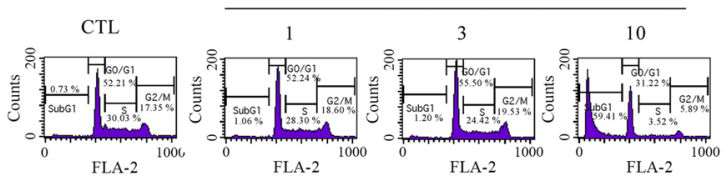

$\mathrm{BA}(\mu \mathrm{M})$
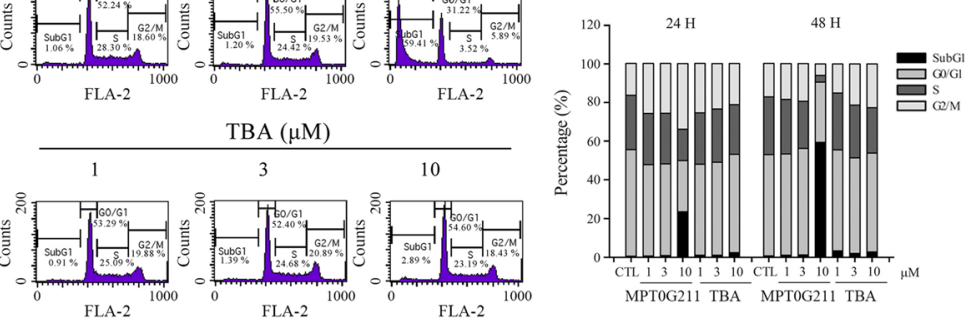

$\mathrm{D}$

MOLT-4

MPT0G211 ( $\mu \mathrm{M})$
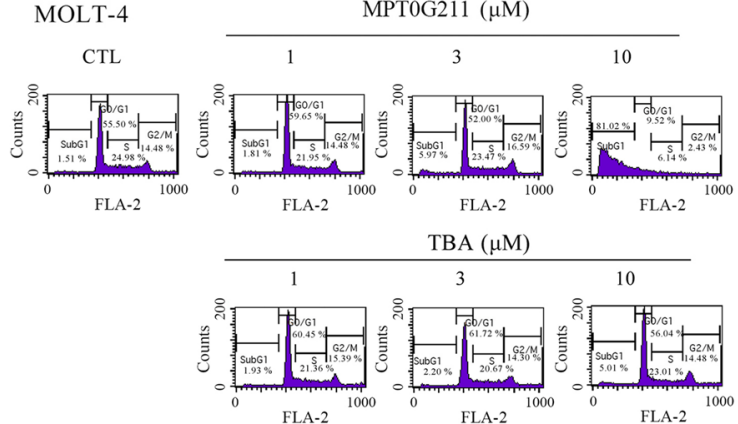

TBA $(\mu \mathrm{M})$
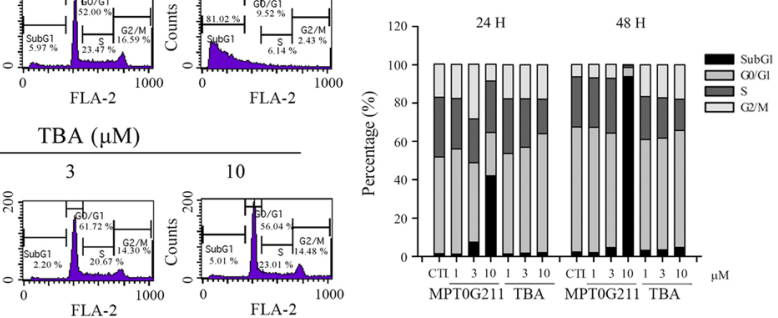

Fig. 1 The effects of MPTOG211 on HL-60 and MOLT-4 cell growth and cell cycle progression. a Acetyl-a-tubulin and acetyl-histone 3 were detected in cells treated with MPTOG211 or tubastatin A (TBA) for $24 \mathrm{~h}$. b HL-60, MOLT-4, and HUVECs were incubated with different concentrations of MPTOG211 or TBA for $48 \mathrm{~h}$. Cell viability was evaluated using an MTT assay. $\mathbf{c}$ HL-60 and $\mathbf{d}$ MOLT-4 cells were treated with MPTOG211 or TBA for $48 \mathrm{~h}$ and analyzed by flow cytometry to assess cell cycle distribution. Data are shown as means \pm standard errors of the means. ${ }^{*} p<0.05$ versus the TBA-treated group 
cells (HUVECs) $\left(\mathrm{IC}_{50}>90 \mu \mathrm{M}\right)$. Subsequently, we used a flow cytometric assay to investigate the effect of MPT0G211 on cell cycle distribution in cells that had been treated with MPT0G211 and TBA for 24 and $48 \mathrm{~h}$. Compared with TBA, treatment with 10 and $3 \mu \mathrm{M}$ MPT0G211 increased the proportions of HL-60 and MOLT-4 cells, respectively, and in the sub-G1 phase at both 24 and $48 \mathrm{~h}$, the effect in the latter cell type was slight but statistically significant (Fig. 1c, d). These data suggest that MPT0G211 is a potent and selective HDAC6 inhibitor that specifically targets malignant cancer cells.

\section{MPT0G211 sensitizes HL-60 cells to doxorubicin-induced cell death}

Combination therapy regimens are usually used to increase the efficacies of chemotherapy drugs, prevent drug resistance, and reduce unwanted side effects during the treatment of acute leukemia. In this study, we subjected HL-60 cells to combined treatment regimens of MPT0G211 with three chemotherapy drugs currently used for acute leukemia: DOXO, VCR, and cyclophosphamide (CTX). The combination index (CI) was used to evaluate the effects of these two-drug combinations, with $\mathrm{CI}$ values of $1,>1$, and $<1$ indicating addiction, antagonism, and synergism, respectively [21]. As shown in Fig. 2a, MPT0G211 $(0.3,1$, or $3 \mu \mathrm{M})$ acted synergistically with DOXO and VCR against HL-60 cells, whereas no obvious synergistic effect was observed with CTX.

Anthracycline drugs such as DOXO are considered standard treatment options for AML. Therefore, we evaluated the effect of a combination of MPT0G211 and DOXO in HL-60 cells. Flow cytometry revealed that this combination significantly induced cell cycle arrest in the G2/M phase, with the subsequent accumulation of cells in the sub-G1 phase (Fig. 2b). Similar effect was also noted in the other AML cell line, MV4-11 (Additional file 1). Moreover, the levels of the apoptotic proteins caspases 3, 8, and 9 and poly-ADP ribose polymerase (PARP) were also increased in these cells following combination treatment (Fig. 2c). TBA was then used to confirm that the synergistic effects of MPT0G211 were mediated through HDAC6 inhibition. In that experiment, TBA also increased the proportion of sub-G1 phase cells when administered in combination with DOXO, although its effects were less potent than those of MPT0G211 (Fig. 2d).

\section{MPTOG211 acetylates Ku70 and regulates Ku70-Bax binding to impair the DNA repair machinery initiated by doxorubicin}

To elucidate the mechanism by which combination therapy induces apoptotic cell death, we examined the levels of the pro-survival proteins BCL-2, BCL-XL, and survivin but observed no changes after treatment with MPT0G211, TBA, DOXO, or a combination treatment
(Fig. 3a). Therefore, we considered the DNA damage response, a process which is centrally regulated by proteins such as ATM and ATR, which cause cell cycle arrest [22] and recruit DNA repair proteins such as Ku70 [23]. Notably, DOXO treatment induced significant phosphorylation of ATM, ATR, and CHK1, which was further enhanced by the combination of MPT0G211 and DOXO; in other words, MPT0G211 can potentiate the DOXO-induced DNA damage response (Fig. 3b).

Furthermore, combined MPT0G211 and TBA treatment induced the acetylation of Ku70 (Fig. 3c), which remained sequestered in the cytosol; accordingly, Ku70 could not sufficiently bind to double-strand break sites to promote DNA repair (Fig. 3d) [24]. In a previous study, acetylation of Ku70 was found to disrupt its bonds with BAX; consequently, free BAX translocates into the mitochondria to induce apoptotic cell death [25]. In this study, we showed that MPT0G211 significantly reduced the binding of Ku70 to BAX (Fig. 3e). We used cell fractionation to further confirm that MPT0G211 facilitates the release of cytochrome $\mathrm{c}$ to the cytoplasm (Fig. 3f) to induce caspase-mediated cell apoptosis. To evaluate that the synergistic effect of DOXO and MPT0G211 can be clinically relevant, we performed this co-treatment in established HL-60 tumor xenograft. Once tumors were palpable (approximately $200 \mathrm{~mm}^{3}$ ), mice were randomized into control (vehicle) and treatment groups. As shown in Fig. $3 \mathrm{~g}$, combination treatment significantly potentiated the antitumor activity of DOXO. The mice tolerated all of the treatments without overt signs of toxicity (Fig. 3h). Taken together, these data indicated that co-treatment of DOXO and MPT0G211 markedly suppressed tumor growth both in vitro and in vivo.

\section{HDAC6 overexpression reverses the synergistic effects of MPTOG211 and doxorubicin}

To validate that the synergistic effect of MPT0G211 and DOXO is truly mediated by the inhibition of HDAC6, we examined whether HDAC6 overexpression could rescue cells from apoptosis triggered by the combined treatment (Fig. 4a). Here, ectopic expression of HDAC6 effectively reduced the expression of caspase 3, PARP, and the DNA damage marker $\gamma$-H2AX (Fig. 4b) while decreasing the proportion of cells in the sub-G1 phase of cell cycle (Fig. 4c, d). Together, these data suggest that the synergistic effects of MPT0G211 and DOXO are mediated through HDAC6 inhibition.

\section{MPTOG211 potentiates vincristine-induced cell arrest on MOLT-4 cells}

We also tested the combined effects of MPT0G211 plus DOXO, VCR, or CTX on MOLT-4 cells (ALL). As shown in Fig. 5a, MPT0G211 $(0.3,1$, or $3 \mu \mathrm{M})$ and various concentrations of VCR exhibited synergistic effects 

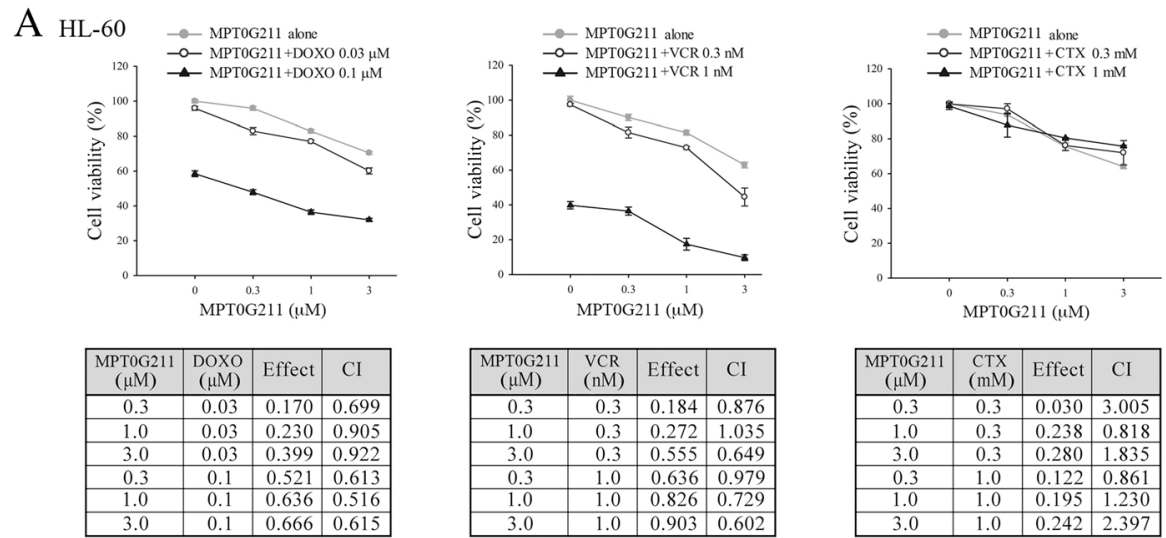

B HL-60

MPT0G211 ( $\mu$ M)
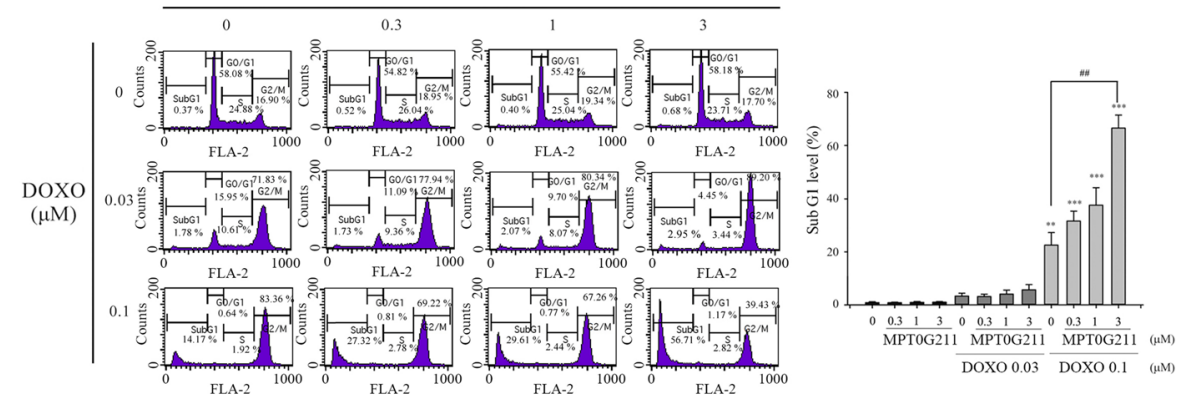

$\mathrm{C}$

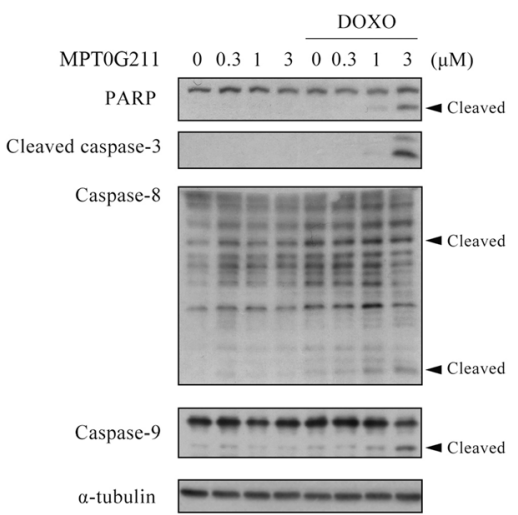

$\mathrm{D}$

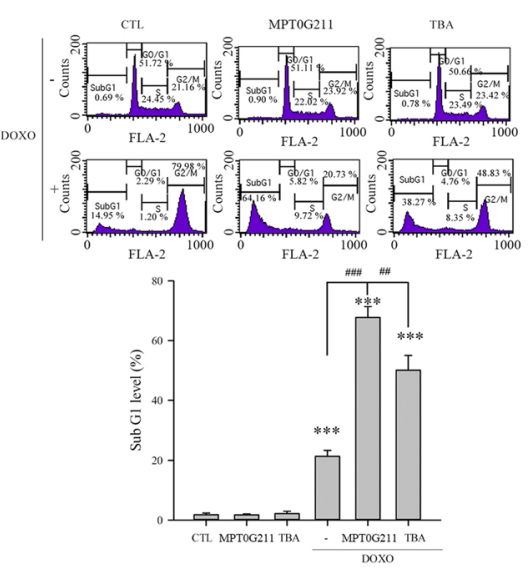

Fig. 2 The combination of MPTOG211 and doxorubicin had a synergistic effect on HL-60 cell death. a The viability of cells treated with MPTOG211 and different doses of doxorubicin (DOXO), vincristine (VCR), and cyclophosphamide (CTX) for $48 \mathrm{~h}$ was tested. The synergistic effects of these drugs were evaluated using the combination index (Cl), with values of $>1.0,1.0$, and $<1.0$ indicating an antagonistic, additive, or synergistic interaction, respectively. b Cell cycle distribution was determined in cells treated with various concentrations of MPTOG211 and DOXO for $48 \mathrm{~h}$. c The combined effect of MPTOG211 and DOXO on the expression of caspases 3, 8, and 9 and poly-ADP ribose polymerase (PARP). $\mathbf{d}$ Flow cytometry was used to evaluate the proportion of cells in the sub-G1 phase of cell cycle following incubation with $3 \mu \mathrm{M}$ MPTOG211 or tubastatin A (TBA) combined with $0.1 \mu \mathrm{M}$ DOXO. Data are shown as means \pm standard errors of the means. ${ }^{*} p<0.05,{ }^{* *} p<0.01$, and ${ }^{* * *} p<0.001$ versus the control group

on the viability of MOLT-4 cells. MPT0G211 induced an increase of cells in the sub-G1 phase at $48 \mathrm{~h}$ in a concentration-dependent manner (Fig. 5b) and induced cell apoptosis via caspase pathway activation and PARP cleavage when combined with VCR (Fig. 5c). And this synergistic effect can also be confirmed in other ALL cell line, CCRF-CEM (Additional file 1). Although TBA also increased the proportion of cells in the sub-G1 phase when used in combination with VCR, this drug had less potent effects than did MPT0G211 (Fig. 5d). 
A $\quad$ HL-60

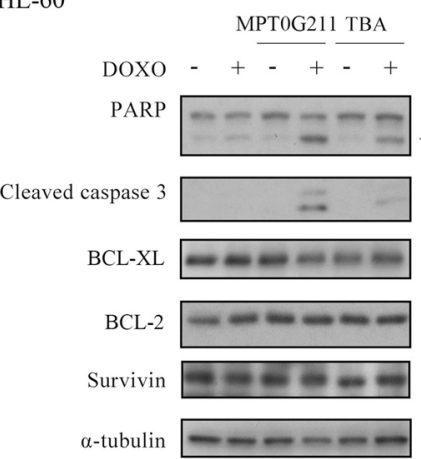

C

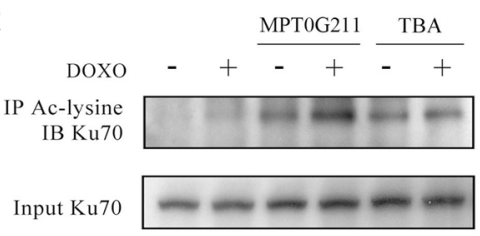

E

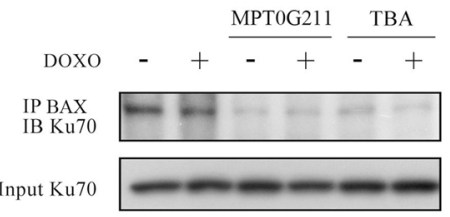

G HL-60

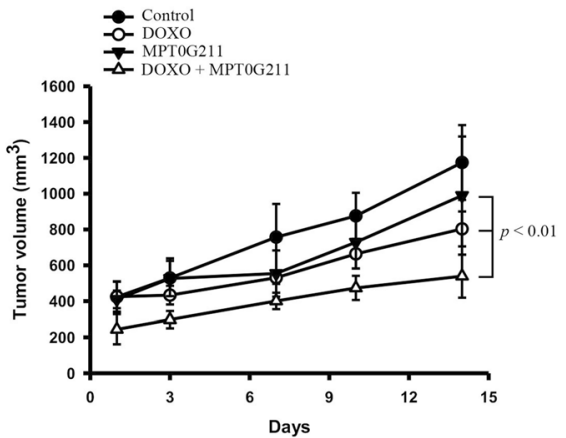

$\mathrm{H}$
B

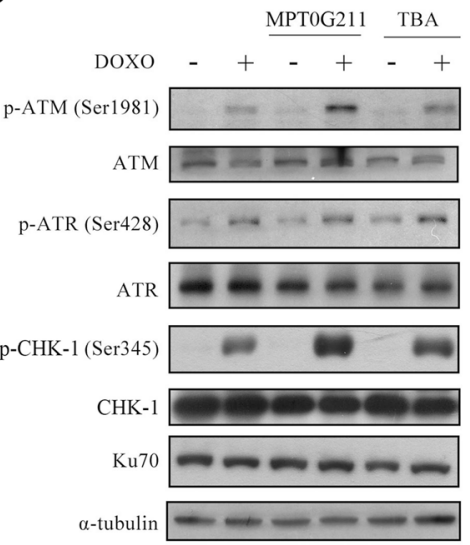

D

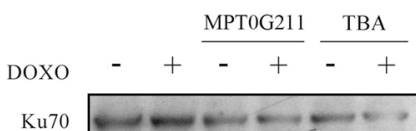

Histone $\mathrm{H} 3$
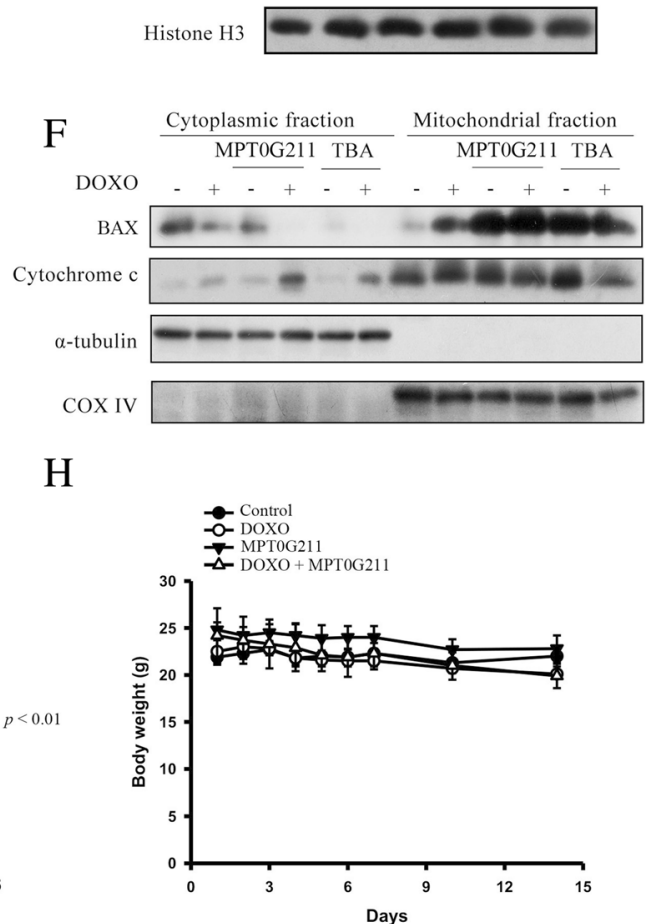

Fig. 3 MPTOG211 potentiates doxorubicin-induced cytotoxicity by increasing apoptosis and decreasing DNA repair machinery in $\mathrm{HL}-60$ cells. a The levels of the apoptotic proteins caspase 3 and poly-ADP ribose polymerase (PARP) and the pro-survival proteins BCL-XL, BCL-2, and survivin were determined in cells treated with MPTOG211 $(3 \mu \mathrm{M})$ or tubastatin A (TBA) $(3 \mu \mathrm{M})$ in combination with doxorubicin (DOXO) $(0.1 \mu \mathrm{M})$ for $24 \mathrm{~h}$. b Co-treatment of MPTOG211 or TBA with DOXO increased the phosphorylation of ATM, ATR, and CHK1 proteins. c The cells were incubated with MPTOG211 or TBA plus DOXO for $24 \mathrm{~h}$, after which total cell lysates were immunoprecipitated with an anti-acetyl-lysine antibody and immunoblotted for Ku70. $\mathbf{d}$ Nuclear Ku70 protein levels were measured in cells treated with MPTOG211 or TBA in combination with DOXO. e Cells were incubated with MPTOG211 or TBA plus DOXO for 36 h, after which total cell lysates were immunoprecipitated with an anti-BAX antibody and immunoblotted for Ku70. $\mathbf{f}$ Cellular distributions of cytochrome $\mathrm{c}$ and BAX after co-treatment with MPTOG211 or TBA plus DOXO. $\mathbf{g}$ Antitumor activity of MPTOG211 plus doxorubicin in a HL-60 xenograft model. When the tumor size reached $200 \mathrm{~mm}^{3}$, mice were injected with vehicle, doxorubicin (1 $\mathrm{mg} / \mathrm{kg}$, i.p., q3d), and MPTOG211 (30 mg/kg, i.p., qd) alone or a combination of both. The curves of tumor growth volume were expressed as mean $\pm \mathrm{SEM}$. $\mathbf{h}$ Changes of body weight after treatment 
A

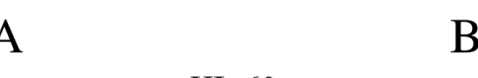

B

HL-60

HDAC6

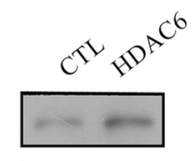

$\alpha$-tubulin

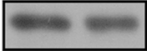

DOXO - $-++\frac{\text { HDAC6 }}{-+++}$

MPT0G211 - $+-+{ }_{-}+-+$

PARP

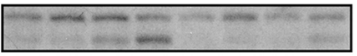

Cleaved

Cleaved caspase-3

$\gamma-\mathrm{H} 2 \mathrm{AX}$

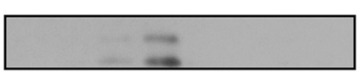

Ac- $\alpha$-tubulin

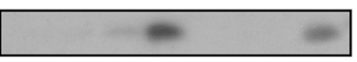

$\alpha$-tubulin

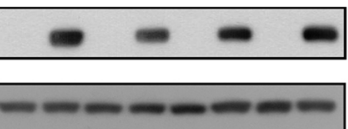

C

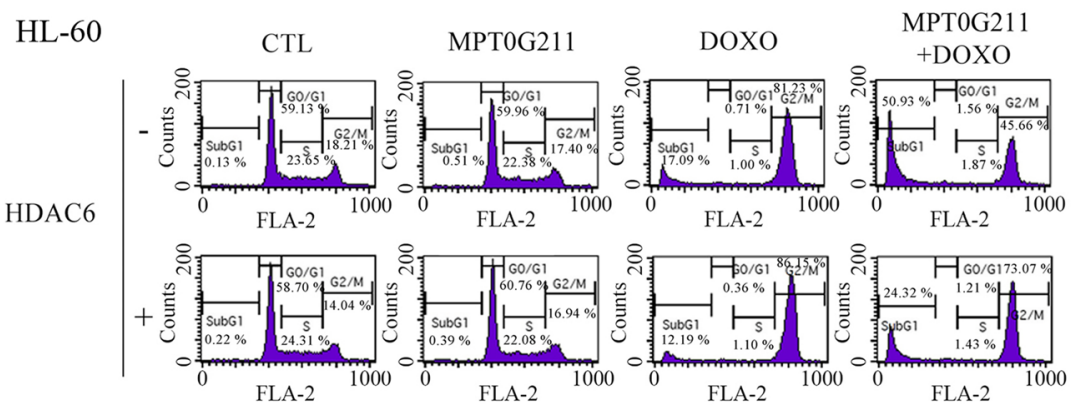

D

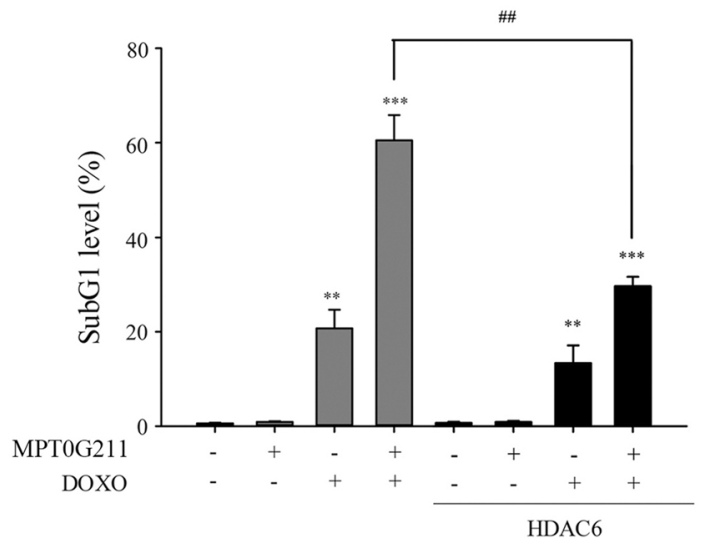

Fig. 4 Ectopic expression of HDAC6 rescues cells from apoptosis induced by MPTOG211/doxorubicin combination. a HDAC6 levels were measured 18 h after transfection with an HDAC6-expression plasmid. b Following co-treatment with MPTOG211 and doxorubicin (DOXO) for $24 \mathrm{~h}$, the levels of the apoptotic proteins poly-ADP ribose polymerase (PARP), caspase 3, $\mathrm{y}-\mathrm{H} 2 \mathrm{AX}$, and acetyl-a-tubulin were measured in HDAC6-overexpressing cells. c Cell cycle distribution was measured in HDAC6-transfected HL-60 cells following treatment with a combination of MPTOG211 and DOXO. A quantitative analysis of the proportions of cells in the sub-G1 phase of cell cycle is shown in $\mathbf{d}$. Data are shown as means \pm standard errors of the means. ${ }^{*} p<0.05$, ${ }^{* *} p<0.01$, and ${ }^{* *} p<0.001$ versus the control group

\section{Combined effects of MPTOG211 and vincristine on microtubule dynamics}

VCR exerts its action by binding to tubulin to inhibit mitosis during metaphase and cause cell apoptosis [26]. We found that MPT0G211 and VCR synergistically led to an increase in cells in the G2/M phase after $24 \mathrm{~h}$ (Fig. 6a), although treatment with these drugs alone or in combination did not affect the levels of the pro-survival proteins BCL-2, BCL-XL, and survivin
(Fig. 6b). However, the drug combination increased the expression of the M phase-regulating proteins MPM2, polo-like kinase (PLK), aurora B, and cyclin B1; additionally, it enhanced the phosphorylation of $\mathrm{CDC} 2$ at Thr161 but suppressed phosphorylation at Tyr15 (Fig. 6c). Finally, immunofluorescence images revealed that the combination of VCR and MPT0G211 more strongly altered microtubule polymerization, compared with VCR alone (Fig. 6d). We further evaluate whether 
A
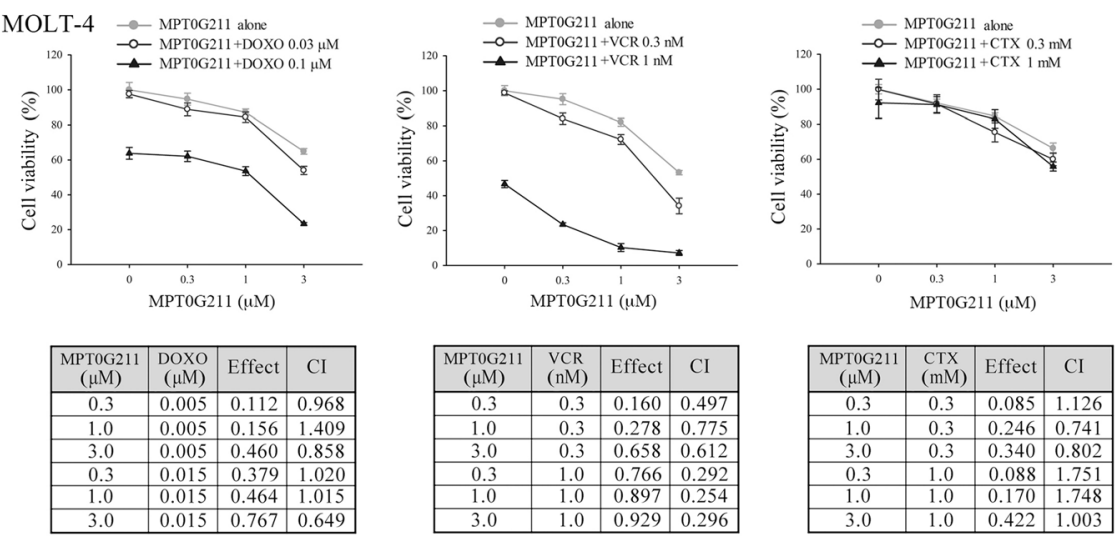

B

MOLT-4

MPT0G211 $(\mu \mathrm{M})$
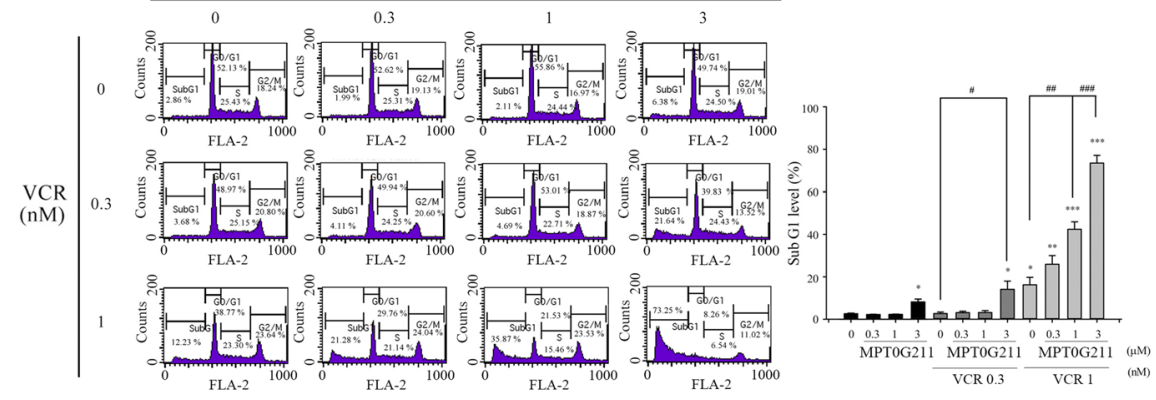

C

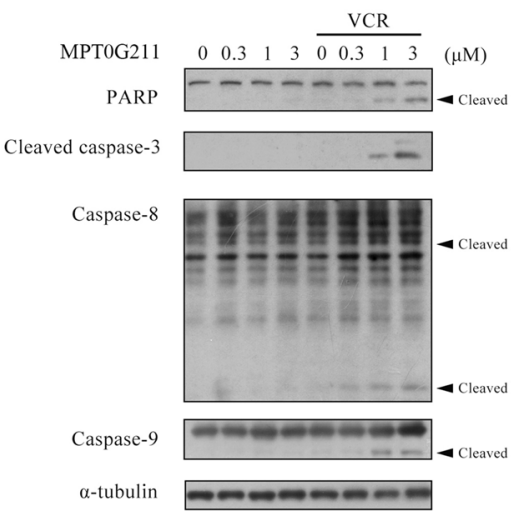

D
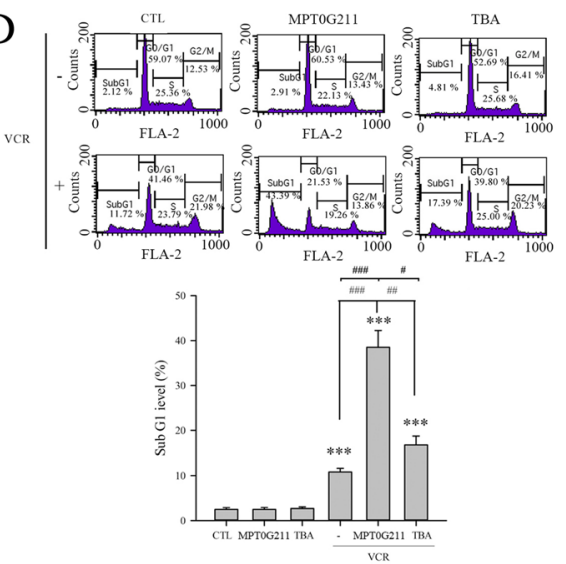

Fig. 5 MPTOG211 potentiates vincristine-induced apoptosis in MOLT-4 cells. a The combined effects of MPTOG211 with doxorubicin (DOXO), vincristine (VCR), or cyclophosphamide (CTX) at the indicated concentrations were evaluated after a 48-h treatment. b Cell cycle distribution was determined after cells were treated with a combination of MPTOG211 and VCR for $48 \mathrm{~h}$. c The combined effects of MPTOG211 and VCR on the expression of caspases 3, 8, and 9 and poly-ADP ribose polymerase (PARP). $\mathbf{d}$ Flow cytometry was used to evaluate the proportions of cells in the sub-G1 phase of cell cycle after incubation with $3 \mu \mathrm{M}$ MPTOG211 or tubastatin A (TBA) together with $1 \mathrm{nM}$ VCR for $48 \mathrm{~h}$. Data are shown as means \pm standard errors of the means. ${ }^{*} p<0.05,{ }^{* *} p<0.01$, and ${ }^{* *} p<0.001$ versus the control group

MPT0G211 could enhance antitumor effect of VCR in mice bearing MOLT-4 xenograft. As shown in Fig. 6e, co-treatment of VCR and MPT0G211 exhibited significant antitumor activity in MOLT-4 tumor xenograft. No significant body weight difference or other adverse side effect was observed (Fig. 6f). Together, these results indicated that concomitant VCR and MPT0G211 can potentiate VCR- induced cell death both in vitro and in vivo.

\section{Discussion}

Although pan-HDAC inhibitors have been approved for the treatment of cancers, currently, they can only be administered to subset of patients with selected hematological malignancies. The use of these drugs is further limited by the frequent clinical observation of negative side effects such as electrocardiographic changes, characterized by T-wave flattening, ST segment 


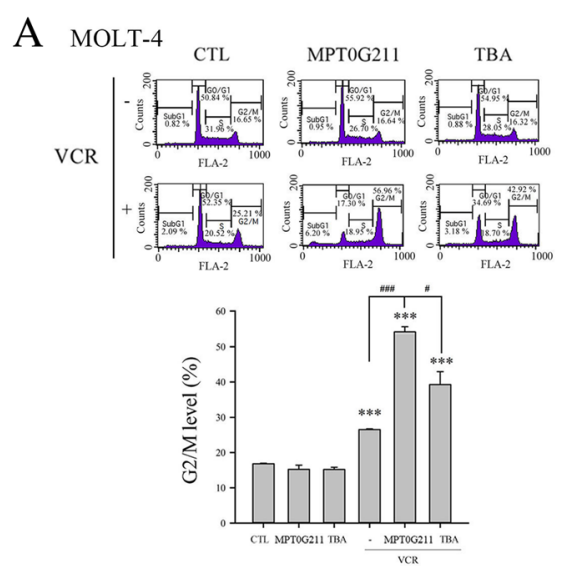

C

D

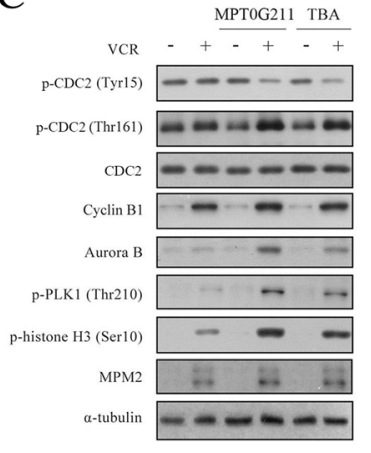

E MOLT-4

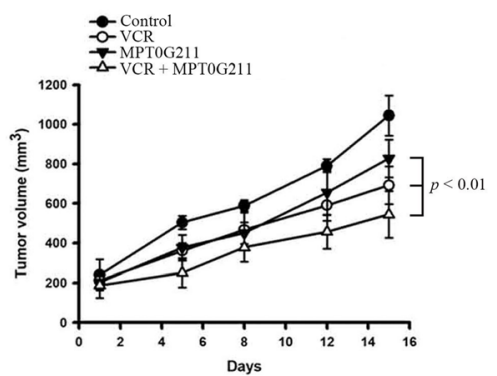

B

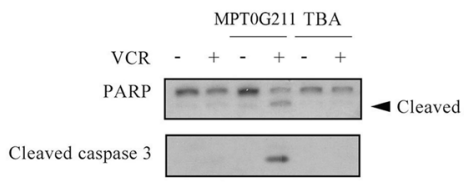

BCL-XL $=-2=-2$

BCL-2 $=-\infty$

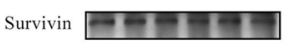

a-tubulin $-----\infty$
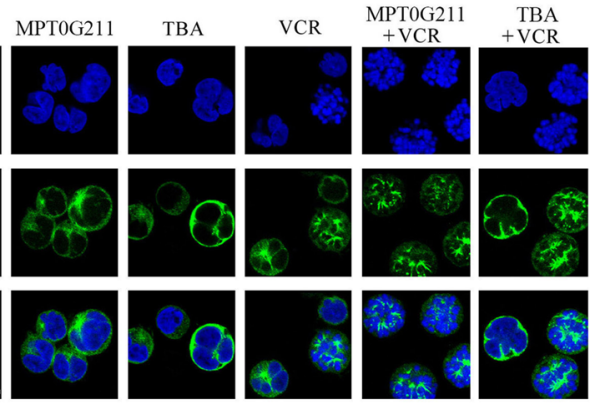

F
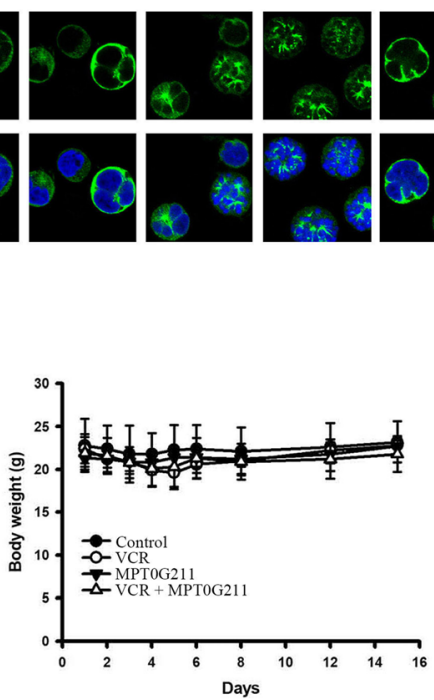

Fig. 6 MPTOG211 sensitized MOLT-4 cells to vincristine-mediated mitotic arrest. a Cell cycle distributions of cells exposed to MPTOG211, tubastatin A (TBA), vincristine (VCR), or the indicated combination therapy for $24 \mathrm{~h}$. A statistical analysis of the proportions of cells in the G2/M phase is shown in the right panel. $\mathbf{b}$ The levels of the apoptotic proteins caspase 3 and poly-ADP ribose polymerase (PARP) and the pro-survival proteins $B C L-X L, B C L-2$, and survivin were determined in cells treated with MPTOG211 $(3 \mu \mathrm{M})$ or TBA $(3 \mu \mathrm{M})$ in combination with VCR (1 nM) for $24 \mathrm{~h}$. c The protein levels of cyclin B1, aurora B, p-CDC2, p-PLK, p-Histone 3, and MPM2 were evaluated following treatment with a combination of MPTOG211 or TBA with VCR for $24 \mathrm{~h}$. $\mathbf{d}$ Cells were co-treated with MPTOG211 or TBA with VCR for $24 \mathrm{~h}$ and incubated with an a-tubulin antibody or DAPI. Microtubule dynamics were evaluated using a ZEISS LS 510META confocal microscope (magnification $\times 630$ ). Scale bar $=20 \mu M$. e Antitumor activity of MPTOG211 plus vincristine in a MOLT-4 xenograft model. When the tumor size reached $200 \mathrm{~mm}^{3}$, mice were injected with vehicle, vincristine (1 mg/kg, i.p., qwk), and MPTOG211 (30 mg/kg, i.p., qd) alone or a combination of both. The curves of tumor growth volume were expressed as mean \pm SEM. $\mathbf{f}$ Changes of body weight after treatment. Data are shown as means \pm standard errors of the means. ${ }^{*} p<0.05$, ${ }^{* *} p<0.01$, and ${ }^{* *} p<0.001$ versus the control group

depression, and QT interval prolongation [11]. In contrast to other HDACs, HDAC6 regulates the acetylation of non-histone proteins such as $\alpha$-tubulin [27], $\beta$-catenin [28], cortactin [29], and heat shock protein 90 [30] and participates in cancer development and progression [13]. The finding that HDAC6-deficient mice is effectively normal, unlike mice deficient in other HDAC isoforms, suggests that HDAC6 inhibition will cause few adverse effects [31]. Therefore, our finding that HDAC6 inhibition by MPT0G211 or TBA did not cause cytotoxic effects on HUVECs is consistent with previous reports. Specifically, we found that although $\alpha$-tubulin acetylation was observed even at low doses $(0.1 \mu \mathrm{M})$ of MPT0G211, high concentrations were required to 
observe the antitumor effects of this drug $\left(\mathrm{IC}_{50}=5.06\right.$ and $3.79 \mu \mathrm{M}$ in HL-60 and MOLT-4 cells, respectively; Fig. 1). Our findings and previous studies in which HDAC6 inhibitors were shown to act synergistically with chemotherapy drugs [32] suggest that such combination therapies may be a rational strategy for the use of HDAC6 inhibitors in cancer treatment.

DOXO, a topoisomerase II inhibitor that induces DNA breakage via intercalation, was reported to induce an increase in the proportion of HL-60 cells in the G2/ $\mathrm{M}$ phase of cell cycle [33]. Consistent with that report, we observed that although MPT0G211 itself had no effect on cell cycle distribution at concentrations below the $\mathrm{IC}_{50}$ value, it potentiated DOXO-induced $\mathrm{G} 2 / \mathrm{M}$ arrest (Fig. 2b). This phenomenon might be due to activation of the ATR-CHK1 pathway [34], as additional research has shown that HDAC6 depletion increases cisplatin-induced cytotoxicity by activating the ATR/ CHK1 pathway in non-small cell lung cancer [35].
Hence, we suggest that MPT0G211 enhances the ability of DOXO to induce ATM, ATR, and CHK1 activation and, consequently, G2/M arrest (Fig. 3b).

The DNA repair process is an important mediator of resistance to DNA targeting drugs [36]. Ku70, a DNA repair protein that binds to the double-strand break ends caused by DOXO, has been reported as a target of HDAC6 [37]. In our study, MPT0G211 induced Ku70 acetylation. This led to the sequestration of Ku70 in the cytosol, which blocked its binding to double-strand breaks (Fig. 3c, d) and therefore impaired DOXO-induced DNA repair. Furthermore, acetyl-Ku70 promoted the dissociation of Ku-70 from BAX, thus promoting BAX-dependent cell apoptosis (Fig. 3e, f). Together, these findings demonstrate the multifaceted ability of MPT0G211 to potentiate the cytotoxic effects of DOXO. We further proved that this ability of MPT0G211 is dependent on the inhibition of HDAC6, as the observed synergistic effects could be reversed by the ectopic expression of HDAC6 protein (Fig. 4).

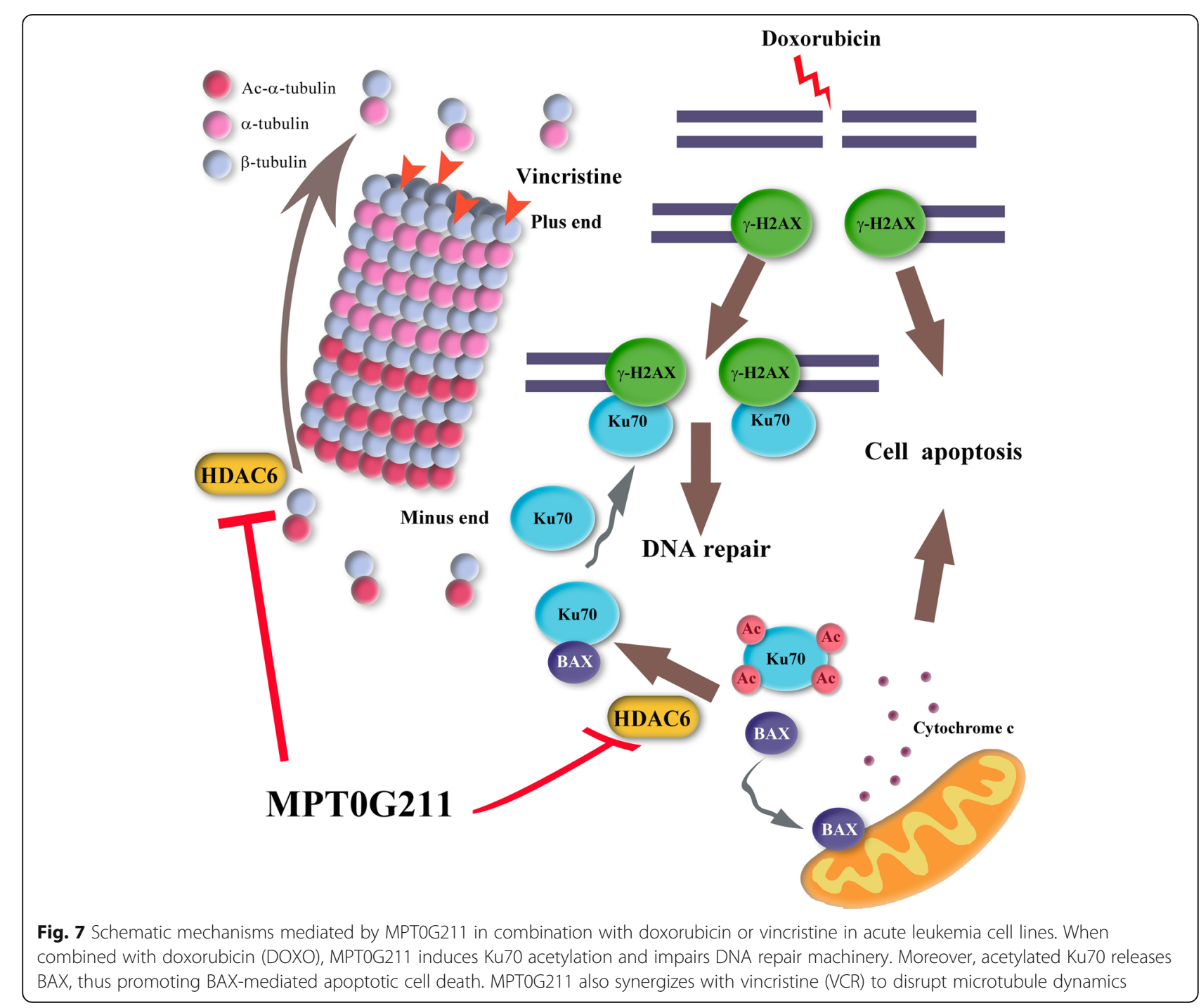


Currently, microtubule-destabilizing agents such as VCR are also considered important for the treatment of ALL. At high concentrations, VCR binds to low-affinity binding sites on microtubule to induce disorganization, whereas at lower concentrations, it interferes with microtubule dynamics without altering polymer levels, leading to mitotic spindle disruption [38]. A previous study demonstrated an increased frequency of multipolar spindle formation in cells co-treated with paclitaxel and the HDAC6 inhibitor, ACY-241 [39]; in other words, the combination of an HDAC6 inhibitor and VCR may also yield therapeutic benefits. Indeed, we found that MPT0G211 potentiated the mitotic arrest induced by VCR (Fig. 5). We further observed that co-treatment with these two drugs altered the phosphorylation pattern of $\mathrm{CDC} 2$, which binds to cyclin B1 and promotes the G2/M transition [40]. Specifically, this combination suppressed the inhibitory phosphorylation of Tyr15 on CDC2 while enhancing the phosphorylation of Thr161 and cyclin B1, which suggests a synergistic effect of these drugs on $M$ phase arrest.

During mitosis, the proteins aurora B and Polo-like kinase 1 are involved in centrosome maturation and mitotic spindle formation [41]. In this study, we demonstrated that co-treatment with MPT0G211 and VCR activated these proteins. Using immunofluorescence images, we also demonstrated that treatment with MPT0G211 or TBA alone had no effect on microtubule distribution, whereas combined treatment with MPT0G211 and VCR led to significant increases in abnormal long astral microtubule formation and chromosome distribution (Fig. 6c). These results were consistent with a previous study in which a combination of the non-selective HDAC inhibitor vorinostat and VCR induced changes in microtubule dynamics [42]. Previously, the HDAC6 inhibitor tubacin was shown to slow microtubule growth by promoting the interaction of HDAC6 with tubulin in a tubulin acetylation-independent manner [43]. Therefore, MPT 0G211 and VCR likely disrupt microtubule dynamics via different mechanisms but act synergistically in combination. We also provide compelling evidence that combined treatment of VCR with MPT0G211 synergistically inhibits the growth of human acute lymphoblastic leukemia cells in animal xenograft.

\section{Conclusion}

In conclusion, our data suggest that compared with TBA, MPT0G211 is a more potent and selective HDAC6 inhibitor than current TBA. Furthermore, the combination of MPT0G211 and DOXO markedly inhibited HL-60 cell survival via apoptosis and interference with DNA repair machinery. Moreover, the combination of MPT0G211 and VCR significantly disrupted microtubule dynamics and induced $M$ stage arrest in MOLT-4 cells (Fig. 7). As HDAC6 inhibitors are at an early stage of clinical development, our findings may provide a novel therapeutic strategy and future applications for cancer therapy.

\section{Additional file}

Additional file 1: Figure S1. The combination effect of MPTOG211 and
chemotherapeutic agent on acute leukemia cell lines. (A) The viability of
cells treated with MPTOG 211 and different doses of doxorubicin (DOXO)
or vincristine (VCR) for $48 \mathrm{~h}$ was tested on CCRF-CEM and MV4-11 cell
lines. The synergistic effects of these drugs were evaluated using the
combination index (CI), with values of > 1.0, 1.0, and < 1.0 indicating an
antagonistic, additive, or synergistic interaction, respectively. (B) Cell cycle
distribution was determined in cells treated with various concentrations
of MPTOG 211 and DOXO for $48 \mathrm{~h}$ on MV4-11 cells. (DOCX $197 \mathrm{~kb}$ )

\section{Abbreviations}

ALL: Acute lymphocytic leukemia; AML: Acute myeloid leukemia;

CTX: Cyclophosphamide; DOXO: Doxorubicin; HDAC: Histone deacetylase; HUVEC: Human umbilical vein endothelial cells; TBA: Tubastatin A; VCR: Vincristine

\section{Acknowledgements}

Not applicable.

\section{Funding}

This study was supported by grants from the National Science Council of Taiwan (MOST106-2320-B-002-006-MY3) and Ministry of Health and Welfare of Taiwan (MOHW105-TDU-PB-211-133004).

\section{Availability of data and materials}

All data generated or analyzed during this study are included in this article.

\section{Authors' contributions}

$Y L, J L, S P$, and $C Y$ initiated the research, developed the concept of the paper, and designed the study. YL performed the in vitro experiments and MC helped to analyze the results. TS, YW, and YC conducted animal studies. JL and $\mathrm{ML}$ designed the synthesized compound. HT wrote the manuscript and interpreted the data. All authors of this paper have read and approved the final version submitted.

Ethics approval and consent to participate Not applicable.

Consent for publication

Not applicable.

\section{Competing interests}

The authors declare that they have no competing interests.

\section{Publisher's Note}

Springer Nature remains neutral with regard to jurisdictional claims in published maps and institutional affiliations.

\section{Author details}

${ }^{1}$ School of Pharmacy, College of Medicine, National Taiwan University, No.33, Linsen S. Road, Taipei 10050, Taiwan. ${ }^{2}$ Graduate Institute of Cancer Molecular Biology and Drug Discovery, College of Medical Science and Technology, Taipei Medical University, Taipei, Taiwan. ${ }^{3}$ Ph.D Program in Biotechnology Research and Development, College of Pharmacy, Taipei Medical University, Taipei, Taiwan. ${ }^{4}$ Ph.D Program for Cancer Molecular Biology and Drug Discovery, College of Medical Science and Technology, Taipei Medical University and Academia Sinica, Taipei, Taiwan. ${ }^{5}$ School of Pharmacy, College 
of Pharmacy, Taipei Medical University, Taipei, Taiwan. ${ }^{6}$ Biomedical Commercialization Center, Taipei Medical University, Taipei, Taiwan.

\section{Received: 30 October 2018 Accepted: 6 December 2018 Published online: 29 December 2018}

\section{References}

1. Arber DA, Orazi A, Hasserjian R, Thiele J, Borowitz MJ, Le Beau MM, Bloomfield CD, Cazzola M, Vardiman JW. The 2016 revision to the World Health Organization classification of myeloid neoplasms and acute leukemia. Blood. 2016;127:2391-405.

2. Fiegl M. Epidemiology, pathogenesis, and etiology of acute leukemia. In: Hiddemann W, editor. Handbook of Acute Leukemia. Cham: Springer International Publishing; 2016. p. 3-13.

3. Chatterjee K, Zhang J, Honbo N, Karliner JS. Doxorubicin cardiomyopathy. Cardiology. 2010;115(2):155-62.

4. Park SB, Goldstein D, Krishnan AV, Lin CSY, Friedlander ML, Cassidy J, Koltzenburg M, Kiernan MC. Chemotherapy-induced peripheral neurotoxicity: a critical analysis. CA Cancer J Clin. 2013;63(6):419-37.

5. Haberland M, Montgomery RL, Olson EN. The many roles of histone deacetylases in development and physiology: implications for disease and therapy. Nat Rev Genet. 2009;10(1):32-42.

6. Seto E, Yoshida M. Erasers of histone acetylation: the histone deacetylase enzymes. Cold Spring Harb Perspect Biol. 2014;6(4):a018713.

7. Ropero S, Esteller M. The role of histone deacetylases (HDACs) in human cancer. Mol Oncol. 2007:1(1):19-25.

8. Mann BS, Johnson JR, He K, Sridhara R, Abraham S, Booth BP, Verbois L, Morse DE, Jee JM, Pope S. Vorinostat for treatment of cutaneous manifestations of advanced primary cutaneous T-cell lymphoma. Clin Cancer Res. 2007:13(8):2318-22.

9. Barbarotta L, Hurley K. Romidepsin for the treatment of peripheral T-cell lymphoma. J Adv Pract Oncol. 2015;6(1):22-36.

10. Libby EN, Becker PS, Burwick N, Green DJ, Holmberg L, Bensinger WI. Panobinostat: a review of trial results and future prospects in multiple myeloma. Expert Rev Hematol. 2015;8(1):9-18.

11. Subramanian S, Bates SE, Wright JJ, Espinoza-Delgado I, Piekarz RL. Clinical toxicities of histone deacetylase inhibitors. Pharmaceuticals (Basel). 2010;3(9): 2751-67.

12. Gryder BE. Targeted cancer therapy: giving histone deacetylase inhibitors all they need to succeed. Future Med Chem. 2012;4(4):1369-70.

13. Aldana-Masangkay Gl, Sakamoto KM. The role of HDAC6 in cancer. J Biomed Biotechnol. 2011;2011:875824.

14. Hackanson B, Rimmele L, Benkisser M, Abdelkarim M, Fliegauf M, Jung M, Lubbert M. HDAC6 as a target for antileukemic drugs in acute myeloid leukemia. Leukemia Res. 2012;36(8):1055-62.

15. Saji S, Kawakami M, Hayashi S, Yoshida N, Hirose M, Horiguchi S, Itoh A, Funata N, Schreiber SL, Yoshida M. Significance of HDAC6 regulation via estrogen signaling for cell motility and prognosis in estrogen receptorpositive breast cancer. Oncogene. 2005;24(28):4531-9.

16. Sakuma T, Uzawa K, Onda T, Shiiba M, Yokoe H, Shibahara T, Tanzawa H. Aberrant expression of histone deacetylase 6 in oral squamous cell carcinoma. Int J Oncol. 2006;29(1):117-24.

17. Bazzaro M, Lin Z, Santillan A, Lee MK, Wang MC, Chan KC, Bristow RE, Mazitschek R, Bradner J, Roden RB. Ubiquitin proteasome system stress underlies synergistic killing of ovarian cancer cells by bortezomib and a novel HDAC6 inhibitor. Clin Cancer Res. 2008;14(22):7340-7.

18. Kanno K, Kanno S, Nitta H, Uesugi N, Sugai T, Masuda T, Wakabayashi G, Maesawa C. Overexpression of histone deacetylase 6 contributes to accelerated migration and invasion activity of hepatocellular carcinoma cells. Oncol Rep. 2012;28(3):867-73.

19. Rey M, Irondelle M, Waharte F, Lizarraga F, Chavrier P. HDAC6 is required for invadopodia activity and invasion by breast tumor cells. Eur J Cell Biol. 2011; 90(2-3):128-35.

20. Lee HY, Nepali K, Huang Fl, Chang CY, Lai MJ, Li YH, Huang HL, Yang CR, Liou JP. (N-Hydroxycarbonylbenylamino)quinolines as selective histone deacetylase 6 inhibitors suppress growth of multiple myeloma in vitro and in vivo. J Med Chem. 2018;61(3):905-17.

21. Ashton JC. Drug combination studies and their synergy quantification using the Chou-Talalay method-letter. Cancer Res. 2015;75(11):2400.

22. Awasthi P, Foiani M, Kumar A. ATM and ATR signaling at a glance. J Cell Sci. 2015;128(23):4255-62.
23. Tomimatsu N, Tahimic CG, Otsuki A, Burma S, Fukuhara A, Sato K, Shiota G, Oshimura M, Chen DJ, Kurimasa A. Ku70/80 modulates ATM and ATR signaling pathways in response to DNA double strand breaks. J Biol Chem. 2007:282(14):10138-45.

24. Chaudhary N, Nakka KK, Chavali PL, Bhat J, Chatterjee S, Chattopadhyay S. SMAR1 coordinates HDAC6-induced deacetylation of Ku70 and dictates cell fate upon irradiation. Cell Death Dis. 2014;5:e1447.

25. Hada M, Kwok RP. Regulation of ku70-bax complex in cells. J Cell Death. 2014:7:11-3

26. Mujagic H, Chen SS, Geist R, Occhipinti SJ, Conger BM, Smith CA, Schuette WH, Shackney SE. Effects of vincristine on cell survival, cell cycle progression, and mitotic accumulation in asynchronously growing sarcoma 180 cells. Cancer Res. 1983:43(8):3591-7.

27. Zhao ZQ, Xu H, Gong WM. Histone deacetylase 6 (HDAC6) is an independent deacetylase for alpha-tubulin. Protein Pept Lett. 2010;17(5):555-8.

28. Li Y, Zhang XW, Polakiewicz RD, Yao TP, Comb MJ. HDAC6 is required for epidermal growth factor-induced beta-catenin nuclear localization. J Biol Chem. 2008;283(19):12686-90.

29. Zhang X, Yuan Z, Zhang Y, Yong S, Salas-Burgos A, Koomen J, Olashaw N, Parsons JT, Yang XJ, Dent SR. HDAC6 modulates cell motility by altering the acetylation level of cortactin. Mol Cell. 2007;27(2):197-213.

30. Kramer $\mathrm{OH}$, Mahboobi S, Sellmer A. Drugging the HDAC6-HSP90 interplay in malignant cells. Trends Pharmacol Sci. 2014;35(10):501-9.

31. Zhang Y, Kwon S, Yamaguchi T, Cubizolles F, Rousseaux S, Kneissel M, Cao C, Li $\mathrm{N}$, Cheng HL, Chua K. Mice lacking histone deacetylase 6 have hyperacetylated tubulin but are viable and develop normally. Mol Cell Biol. 2008;28(5):1688-701.

32. Namdar M, Perez G, Ngo L, Marks PA. Selective inhibition of histone deacetylase 6 (HDAC6) induces DNA damage and sensitizes transformed cells to anticancer agents. Proc Natl Acad Sci U S A. 2010;107(46):20003-8.

33. Zuryn A, Litwiniec A, Klimaszewska-Wisniewska A, Nowak JM, Gackowska L, Mysliwiec BJ, Pawlik A, Grzanka A. Expression of cyclin D1 after treatment with doxorubicin in the HL-60 cell line. Cell Biol Int. 2014;38(7):857-67.

34. Peng ZG, Yao YB, Yang J, Tang YL, Huang X. Mangiferin induces cell cycle arrest at G2/M phase through ATR-Chk1 pathway in HL-60 leukemia cells. Genet Mol Res. 2015;14(2):4989-5002.

35. Wang L, Xiang SY, Williams KA, Dong HQ, Bai WL, Nicosia SV, Khochbin S, Bepler G, Zhang XH. Depletion of HDAC6 enhances cisplatin-induced DNA damage and apoptosis in non-small cell lung Cancer cells. PLoS One. 2012; 7(9):e44265.

36. Schonn I, Hennesen J, Dartsch DC. Ku70 and Rad51 vary in their importance for the repair of doxorubicin- versus etoposide-induced DNA damage. Apoptosis. 2011;16(4):359-69.

37. Subramanian C, Jarzembowski JA, Opipari AW Jr, Castle VP, Kwok RP. HDAC6 deacetylates Ku70 and regulates Ku70-Bax binding in neuroblastoma. Neoplasia. 2011;13(8):726-34.

38. Mollinedo F, Gajate C. Microtubules, microtubule-interfering agents and apoptosis. Apoptosis. 2003;8(5):413-50.

39. Huang $P$, Almeciga-Pinto I, Jarpe $M$, van Duzer JH, Mazitschek R, Yang $M$, Jones SS, Quayle SN. Selective HDAC inhibition by ACY-241 enhances the activity of paclitaxel in solid tumor models. Oncotarget. 2017:8(2):2694-707.

40. Dash BC, El-Deiry WS. Phosphorylation of p21 in G2/M promotes cyclin BCdc2 kinase activity. Mol Cell Biol. 2005;25(8):3364-87.

41. Jackson JR, Patrick DR, Dar MM, Huang PS. Targeted anti-mitotic therapies: can we improve on tubulin agents? Nat Rev Cancer. 2007;7(2):107-17.

42. Chao MW, Lai MJ, Liou JP, Chang YL, Wang JC, Pan SL, Teng CM. The synergic effect of vincristine and vorinostat in leukemia in vitro and in vivo. J Hematol Oncol. 2015:8:82.

43. Zilberman Y, Ballestrem C, Carramusa L, Mazitschek R, Khochbin S, Bershadsky A. Regulation of microtubule dynamics by inhibition of the tubulin deacetylase HDAC6. J Cell Sci. 2009;122(Pt 19):3531-41. 